\title{
Exploration of Cultural Introduction in College English Language Teaching
}

\author{
Ping Wang \\ Hubei University of Traditional Chinese Medicine, Wuhan, Hubei 430065, China
}

Keywords: College English; teaching; cultural introduction

Abstract: Language and culture are complementary and inseparable. Languages without cultural connotation can be said to be similar in taste. Culture introduction in English language teaching is indeed worthy of attention. College English teaching has higher education than general English teaching, which requires that the cultural penetration in College English language teaching will help solve the multiple problems that arise in College students' English learning, enrich the content of the English class, and at the same time enhance students' interest in learning English, so as to achieve a higher quality of learning and better teaching results.

\section{Introduction}

English teaching has always been valued by the national education department. The primary English teaching in primary schools has been extended to the more professional English teaching in universities. The knowledge content in English teaching has been refined, and at the same time, the teaching effect of the education department on English teaching Requirements and educational goals have been changing with the development of the times. The introduction of English teaching culture has become an increasingly important teaching goal. Basic elementary English teaching courses require teachers to teach children the basic knowledge and principles of English language. During the middle school, English courses begin to emphasize students' oral communication and English listening ability. College English as a more sophisticated teaching curriculum has higher teaching requirements. The "English Teaching Syllabus for Colleges and Universities" revised in 2000 clearly stipulates that in college English teaching, teachers should pay attention to developing students' intercultural communicative competence. It can be seen that the process of college English teaching requires the introduction and infiltration of culture. Learning for a language cannot stop at basic word recognition and grammar, but it must change from learning basic knowledge to understanding cultural characteristics. Importing has become an important part of the teaching process.

\section{Cultural and Language Teaching}

As the world's most extensive second language, English plays an important role in many areas of education and non-education. In the field of education, learning English has always been a task of language learning that is highly valued by the country and society. 
Learning English helps to integrate with the international community. In Western countries, English is the official language used by most countries. It can be seen that English carries the cultural wealth of many countries. The cultural background of a language is immeasurable. The analogy scientists inferred the economic and political conditions of the Shang Dynasty from the study of Oracle, and the cultural connotations recorded in English are equally important. Culture refers not only to simple literature, music, and art, but also encompasses the general pattern of a racial social system, religious beliefs, educational thinking, and technological development.

\subsection{English language plays an important role in culture}

English also plays a key role in Western culture. We can learn about the social background, lifestyle and mode of thinking of Western countries from the process of learning English. Gudinaf said: The language of a society is an aspect of the culture of the society, and language and culture are part and whole. Teachers in the teaching of the English culture contained in the students into the task of learning can provide students with the opportunity to understand the Western culture and promote the enthusiasm of the students' English learning. A single model of knowledge teaching has failed to satisfy the increasingly thirsty curiosity of modern college students. The infiltration of culture in teaching can open a door for students to the exotic world. Students also learn about foreign culture while learning about foreign culture. The method of acting for others in different social contexts also meets the requirements of the Ministry of Education for college English teaching.

\subsection{Analysis of the status quo of English language teaching}

Although the "Learning Syllabus for Colleges and Universities" stipulates new goals and directions for college English teaching, the real implementation and popularization is a slow and full of difficulties and obstacles. With regard to high standards of education goals and requirements, teachers in big cities have more opportunities and ways of receiving emerging information, and are more capable of accepting new things. Most teachers can change their own teaching methods according to the new teaching strategy. For schools in remote areas, the channels for teachers to accept information are not rich enough. Teachers have long been in an environment where news is blocked. There is not much opportunity for them to be exposed to new things, and their corresponding ability to receive information is not stimulated and consolidated. There is a certain degree of difficulty in understanding the new educational goals. It takes time to collect information to understand and thoroughly understand the teaching philosophy. Then we can begin to improve education methods. In the same way, children in remote areas may receive more new channels than their teachers in the same area, and the corresponding ability to accept them will also be different from that of students in high-speed development centers. Therefore, in order to achieve cultural penetration in college English language teaching, it is worthwhile for the education department to pay attention to the training of teachers. When teachers are required to improve the quality of teaching, they must pay more attention to the cultivation of teachers themselves. Regular education seminars conducted by the education department are a good opportunity for exchanges. This state should continue to be maintained. At the same time, it is necessary to develop more innovative concepts for teachers in peripheral cities. The important task of the introduction of the English language teaching culture needs to start from the two aspects of teachers and students at the same time, and promote the common learning and progress of the two parties in order to win the final win-win situation. 


\section{The Necessity of Cultural Introduction of College English Language Teaching}

\subsection{Cultural Introduction and English Teaching Reform}

Cultural introduction is a necessary condition for the reform of college English teaching. The focus of English teaching content is gradually shifting, from the earliest word recognition of English words, to the emphasis on students' pronunciation of English words and sentences, and finally the direction of flexible use of spoken English in the complete context. From "dumb" English to awkward reading sentence sentences, to the ultimate use of English in the actual exchange of conversation, and create a harmonious atmosphere of English conversation, in order to achieve our final requirements. The English teaching reform aims to teach students more sophisticated and effective learning methods and language skills. Cultural introduction is in line with the requirements of reform goals.

\subsection{Cultural Introduction and Cross-Language Communication}

The introduction of culture facilitates cross-language exchanges. Under the current backdrop of rapid economic development, economic and trade exchanges between China and foreign countries are increasingly frequent and close. In the process of friendly cooperation, both parties should not only pay attention to the interests of the two parties involved, but also must carry out bidirectional output and exchanges of different cultures. The direction of economic development influences the career planning direction of college students in the future. The development mode of Sino-foreign cooperation also implies an increasingly important influence position occupied by English culture. Understanding English culture will become an advantage that college students can demonstrate in the process of seeking employment for international companies in the future, which is conducive to the improvement of the college students' cultural quality.

\subsection{Cultural Import and Communicative Competence}

The teaching of cultural knowledge is an important part of language and culture teaching. The development of communicative competence is the ultimate goal and requirement of language teaching. The most fundamental task of English teaching is to realize the goal that students can use English to communicate fluently. Language learning is a key step in improving the ability of communication. University life is a combination of school-style life and social life. The university can be said to be the final course for students to enter the society. After entering the society, students need to have the ability to integrate with the society. The improvement of interpersonal skills is absolutely the most important task. The communicative competence not only requires the proficient use of language, but also requires the combination of language skills and cultural background. Only when both the language-based skills and the linguistic and cultural background are proficient in the two parts can we achieve better and more efficient communication with people.

\section{The Strategic Principles of Cultural Introduction to College English Language Teaching}

\subsection{Comparison of teaching principles}

The cultural contrast teaching method is conducive to the introduction of culture in the teaching process. The central concept of contrastive teaching is "seeking common ground while reserving differences", which means to popularize differences in Chinese and foreign cultures and introduce similarities. The integration of Chinese and foreign cultures in specific teaching enables students to 
have a deeper understanding of cultural differences between China and foreign countries. For example, we can start with religious beliefs. Most Americans are Christians and believe in Jesus. The Christmas of the United States is to commemorate Jesus. The importance of Christmas to the United States is equivalent to the importance of the Spring Festival to China. Christ Jesus has a great influence on American religious culture and even social culture. By comparing differences and analogies of the same type, students can understand the Western culture more intuitively.

\subsection{Adapt to the principle of scientific and technological development}

The rapid development of information technology has led to the development of teaching technology, and multimedia teaching methods have gained popularity. Teachers should follow the development of the times, learn to use multimedia technology to enrich classroom content, and improve teaching methods. Making PPT courseware has become the daily requirement of most colleges and universities for teachers. This is a good development phenomenon, but only the teaching methods of PPT teaching can't meet the needs of students for knowledge richness. In addition to the way PPT assists classroom teaching, teachers can also add materials such as audio, video, and literary content, introduce new things in a variety of ways, and lead students to learn to enrich cultural content while also applying the high-tech equipment of the school. .

\subsection{Feedback after school}

The focus of cultural introduction should not only be implemented in the classroom, but also take appropriate measures to arouse the attention of students during the time of class. The method of fragmented teaching is worth adopting. Teachers can guide students to use the fragmented time to supplement the learning and understanding of culture under the course of the lesson, and use the products of the times (WeChat, qq and other communication software) to guide and feedback. Use communication software that facilitates communication to establish a class study group. In class time, students can share some interesting stories about western culture, discuss and encourage students to express their opinions, and increase their awareness of western culture in communication.

\section{The Method of Cultural Introduction in College English Language Teaching}

\subsection{Change stages}

The introduction of cultural content in traditional teaching content is a process that requires gradual and orderly progress. The excessively large teaching methods will make students unable to adapt well in a short period of time. We advocate changing in stages. You can start with what you teach in class and add interesting topics to stimulate students' curiosity. For example, you can tell students about the origins and customs of Halloween: Halloween was traditionally called the "Ghost Festival" by the Celts, Celtic. In order to drive away the dead souls and ghosts who wandered in the world, ethnic people wear different kinds of ugly masks to dress themselves. Now, the more popular custom is that children dress up as monsters and carry pumpkin lanterns. If you knock on the door to ask for candy, people who knock on the door will have to bear the consequences of being kidnapped if you don't give candy. That is, people often say, "If you don't give sugar, it's a trick."

\subsection{Enrich classroom content}

Add some interesting science knowledge in the classroom or carry out some related seminars to 
enrich the classroom content, so that students experience more happiness in boring knowledge learning, so as to enhance the completion of the learning task. On this basis, teachers can selectively recommend some English film and television works, music works and literary works. Students are encouraged to actively engage with relevant information in English after school hours. Students have more opportunities to contact English to understand the English language environment. This kind of spontaneous activity can enhance students' interest in English from the inside out, so that learning English is no longer a simple task, but can be transformed into a part of their own interests.

\subsection{Role playing}

The cultural infiltration in the classroom can broaden students' knowledge, organize students to play roles in setting situations, and perceive the rich content of culture through the form of scenario reproduction is also a good teaching method. Set specific cultural backgrounds and social backgrounds to allow students to reflect on the implications of Western culture from a new perspective through their roles. The specific scenes and characters of role-playing can be searched for from the classic film and television works, with reference to the classic film and television clips, through the second presentation, allowing students to put themselves into it, to experience and perceive the culture. The penetration of culture in the teaching process needs to start with the explanation of specific cases and the role-play as a consolidation method. The combination of the two should be carried out in a step-by-step manner.

\subsection{Strengthen interaction}

Under the background of the increasingly developed communication tools, the educational facilities in universities are increasingly refined and perfected. Teachers should learn to use these new technological products to interact with students and use them to train students in the use of English language communication skills. It can achieve the effect of making English applications more daily, and it can also be used as learning feedback after class, in the exchange, students' mastery of what they have learned is found out, and problems are eliminated. The students' shortcomings are further stipulated in the next teaching task. The method of English language teaching should keep pace with the times and keep pace with the progress of the times, so as to better adapt to the pace of development of the times.

\section{Conclusion}

Culture is the soul of the nation. Combining western culture with English language teaching helps students to understand the essence of the national culture of Western culture and is of great significance to the future development of the students' academic career. The introduction of culture in English language teaching is a teaching task that is worthy of attention. It is extremely important for both the development of students' learning and the improvement of teachers' teaching methods. It is hoped that the majority of educators can recognize the importance of cultural introduction, be able to comprehend the essence of cultural introduction, and formulate an adaptive teaching plan based on their own teaching environment.

\section{References}

[1] Gao Yansong. Cultural Introduction in College English Teaching [D]. Changchun University of Technology, 2013.

[2] Chen Shen. "Language Culture Teaching Strategy Research" [M]. Beijing: Language and Culture University Press, 2001.

[3] Gao Yan. Cultural introduction in college English teaching [D]. Shandong Normal University, 2011. 